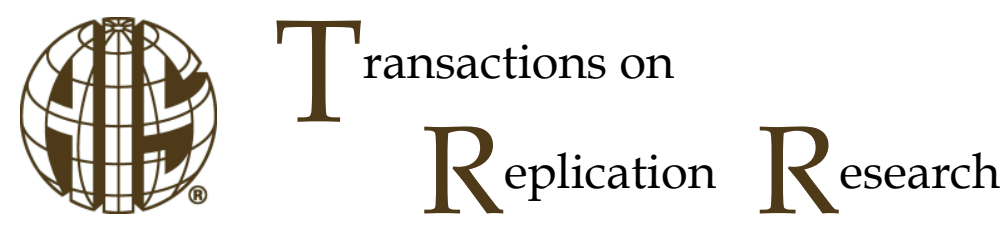

Conceptual Replication

ISSN 2473-3458

\title{
Continuance Intention on Using Mobile Banking Applications: A Replication Study of Information Systems Continuance Model
}

\author{
Ali Vedadi \\ Dept. of Management \& Information Systems \\ Mississippi State University \\ av540@msstate.edu
}

\author{
Merrill Warkentin \\ Dept. of Management \& Information Systems \\ Mississippi State University \\ m.warkentin@msstate.edu
}

\begin{abstract}
:
One of the most significant factors to the survival of many service-based firms such as banks and insurance companies is customers' continuous use of their IT services. The focus of this paper is on replicating IS Continuance Model (Bhattacherjee, 2001) in the mobile banking context. We collected data by surveying 256 college students who were users of mobile banking applications of multiple banks in the U.S. The hypotheses were also tested using Structural Equation Modeling technique (SEM), with AMOS version 23. All five hypotheses of the model were supported, with $67 \%$ explained variance for the "continuance intention," as the dependent variable. Our findings show that the IS Continuance Model, which was originally tested by surveying the users of web-based banking services of one bank, is supported in a modern related context and is generalizable to the mobile banking applications users.
\end{abstract}

Keywords: IS Continuance Model, Continuance Intention, Satisfaction, Confirmation, Perceived Usefulness, Structural Equation Modeling, Mobile Banking Applications

The manuscript was received 12/10/2015 and was with the authors 3 months for 1 revision.

\section{Introduction}

One of the central elements to the survival of many service-based firms such as banks and insurance companies is their customers' continuous use of IT services. Furthermore, the 80/20 rule in marketing suggests that a small number of heavy users constitute most visits to a site, indicating the crucial nature of continued use in the business-to-consumer context (Schmittlein et al., 1993; Kim \& Malhotra, 2005). In this regard, Bhattacherjee (2001) published one of the earliest and most cited scholarly papers in the IS field that conceptualizes and tests a theoretical model of IT continuance that takes into account the distinctions between adoption and continued use of IT. This paper is credited with creating a new stream of research on technology continuance. The proposed model is based on Expectation-Confirmation Theory (ECT), adapted from the marketing literature (Oliver, 1980). The model is empirically validated using data from a field survey of online banking users. The primary objectives of Bhattacherjee (2001) include (1) identifying the salient factors underlying users' intention to continue using a technology after its initial acceptance, and (2) understanding how these motivations influence continuance intention beyond initial adoption.

Our paper is focused on replicating the same research model in the mobile banking context. With the proliferation of smartphones, mobile banking is gradually usurping the traditional web-based online banking. Mobile banking is centered on transaction-related features such as bill payments and check deposits and also offers additional security by text-banking feature, as an extra form of authentication. Therefore, the motivation of our study is to investigate the validity and generalizability of Bhattacherjee's IS Continuance Model in the mobile banking context. The paper is structured as follows. First, we briefly address the role of replication research and of theory contextualization. Then, we briefly review the relevant literature and underlying concepts of the original paper. Following this, we describe the research methodology. Finally, the results are presented and discussed. 


\subsection{Replication Research}

Dennis \& Valacich (2014) argue that replication studies can provide "external third-party validation" of the results of published scientific articles, and can also offer "generalization of the original contribution into a new context." When a replication fails to support the earlier findings, it is argued that scientific knowledge can be established by seeking to show the extent to which the original theories or methods can be extended or generalized, especially beyond the original boundary conditions into new contexts. Recent scholars have called for greater theory contextualization in an effort to improve the rigor of our theoretical lenses. Johns (2006) discusses how context can influence theory and theorizing. Salovaara \& Merikivi (2015) suggest that by re-examining published studies to verify or extend their findings, we offer the opportunity to increase our knowledge of existing theories' boundary conditions and strengthens the research community by accelerating the exchange of interaction between researchers. Seddon \& Scheepers $(2012,2015)$ reiterate this research guideline and suggest that extant works be tested for refinement of boundary conditions, whether or not the original findings can be replicated in the new environment. Furthermore, Joshi \& Roh (2009) provide a roadmap for context-focused research, and urge researchers to more carefully account for context in their research, which will facilitate greater theoretical integration of the macro and micro levels of analysis and will pave the way for new theoretical developments. Context has been defined (Cappelli \& Sherer, 1991) as the surroundings that help illuminate the focal phenomenon, whereas Johns (2006) defined context as the surrounding phenomena (external to the focus of the study, such as the individual) which often exist at a different level of analysis. Hong et al. (2013) argue for the importance of context in theory development and identify meaningful ways that IS research studies have been (and can be) replicated or extended into new contexts, in order to establish construct validity in cross-context research. In this way, theories are strengthened and improved (Whetten et al., 2009). Our study can extend and strengthen the applicability of an established theory, and provide a contribution whether or not the original findings are supported in the new context. As recently observed (Olbrich et al., 2016), rejecting a hypothesis plays a crucial role in a positivist epistemology, and when extending theory with a contextualized replication, Olbrich et al. (2016, p. 15) point out that divergence from original findings "should lead to deeper questions."

\section{Theoretical Framework and Hypotheses}

Drawing on ECT, Bhattacherjee (2001) argues that users' IS continuance intention is determined primarily by their satisfaction with prior IT use. This argument is further strengthened by citing an Inteco's study in which negative experiences and dissatisfaction resulting from slow access or engaged lines, poor help lines, and other technical problems as users' primary reasons for service termination. Satisfaction is an affect, captured as a positive (satisfied), indifferent, or negative (dissatisfied) feeling. Affect has been theorized and validated in TRA-based studies as an important predictor of intention concerning technology use (Karahanna et al., 1999; Taylor \& Todd, 1995a; Taylor \& Todd, 1995b).

Additionally, De Guinea \& Markus (2009) argue that IT continuance behaviors are also shaped by emotive concepts such as satisfaction which should be viewed as an experiential response to IT usage. Satisfaction is irrelevant to initial IT acceptance given the lack of IT experience before acceptance. However, in continuance contexts, satisfaction with prior usage as the primary antecedent of IT continuance perhaps becomes even more dominant than perceived usefulness, because users tend to ascribe more faith in their actual experiences (as captured by satisfaction) than in relatively unknown future expectations (Bhattacherjee, 2001). Hypotheses of our study are as follows:

Hypothesis 1: Users' level of satisfaction with initial use of mobile banking applications is positively associated with their continued intention of using these apps.

Hypothesis 2: Users' extent of confirmation is positively associated with their satisfaction with using these apps.

Hypothesis 3: Users' perceived usefulness of mobile banking applications is positively associated with their satisfaction with using these apps.

Hypothesis 4: Users' continuance intention of using mobile banking applications is positively associated with their perceived usefulness of these apps.

Hypothesis 5: Users' extent of confirmation is positively associated with their perceived usefulness of mobile banking applications. 
The hypothesized model is as follows:

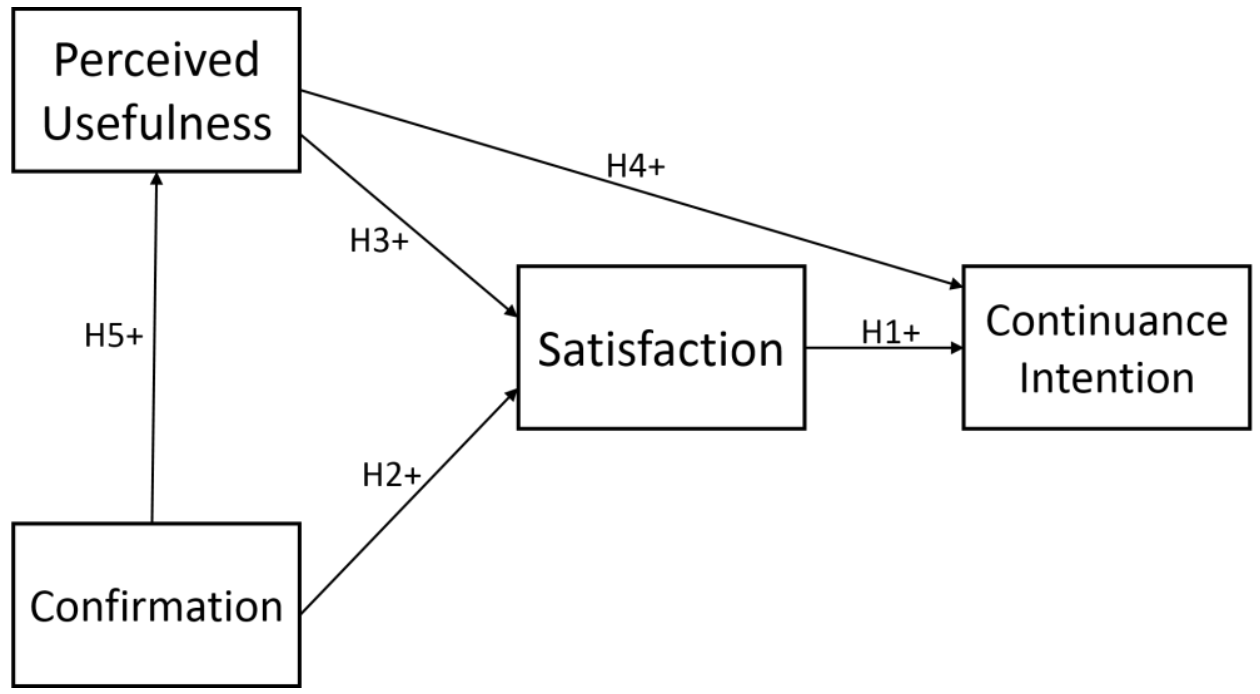

Figure 1. Research Model

\section{Method}

Dennis \& Valacich (2014) have classified replication research into three main categories - exact, methodological, and conceptual. This research fits into the conceptual category which is defined as "the strongest form of replication because it ensures that there is nothing idiosyncratic about the wording of items, the execution of treatments, or the culture of the original context that would limit the research conclusions." After confirming with the Editors of AIS Transactions on Replication Research, we proceeded to implement selected modern methodological improvements designed to introduce greater rigor to the data collection and analysis process, as outlined below, while maintaining a conceptual replication protocol.

We used the same theory (Expectation-Confirmation Theory) and the same data collection method (crosssectional surveying) as the original study, but unlike the original study, in which the customers of only one bank are surveyed, our sampling frame included customers of multiple banks in the United States. Before starting the data collection process, we convened an expert panel review with a group of faculty members and doctoral students to assess the face validity of the items (Hardesty \& Bearden, 2004). Then we held a meeting with a group of individuals from the same population used in our primary data collection to receive further feedback and guidance on wording, layout, and overall readability. After applying the results of this feedback, we designed the final online survey and invited 529 students in a large public university in the U.S. to participate in the survey. The survey included 10 items with seven-point fully-anchored Likert scales ranging from 1 = strongly disagree, 2 = moderately disagree, 3 = slightly disagree, 4 = neutral, 5 = slightly agree, $6=$ moderately agree, to $7=$ strongly agree and 4 items with semantic differential scale to measure satisfaction. The items were also randomized in the online survey in order to control for common-method bias (Podsakoff et al., 2003). We also included one attention check question to identify and eliminate data from respondents who were answering without carefully reading each item.

We received 396 responses (a 75\% response rate), of which 42 cases were removed because of the wrong answer to the attention check question. Additionally, we identified and rejected 27 cases because of response set (Andrich, 1987; Kerlinger, 1973; Rennie, 1982). The remaining cases were then tested for detecting outliers using Mahalanobis Distance test (cases with probability less than 0.001 were dropped) and 71 cases were deleted (McCune \& Grace, 2002). Finally, we used the remaining 256 cases for data analysis, representing a usable sample of $48 \%$ of those originally invited. The respondents' average age was 22.6 years with a 2.98 years of experience with using mobile banking applications. Consistent with the original study, we used a Structural Equations Modeling approach to test the hypotheses and AMOS version 23 was used to run the model. The next section discusses the results of measurement and structural tests. 


\section{Results}

\subsection{Measurement Validity}

In order to test the validity of the four constructs, we used confirmatory factor analysis (CFA) and maximum likelihood approach. All scale items were modeled as reflective indicators of their respective hypothesized constructs. We began with an exploratory factor analysis as an initial validity check (see Appendix A) and all items loaded on the predicted factors.

The goodness-of-fit of the overall CFA model was assessed by examining the chi-square square normalized by degrees of freedom that should be above 5 (Bentler, 2006), Normed Fit Index (NFI) and Comparative Fit Index (CFI) which should exceed 0.9. In this model, the chi-square normalized by degree of freedom was 1.961, Normed Fit Index equaled 0.957 and Comparative Fit Index was 0.978 . The root mean square error of approximation (RMSEA) was also equal to 0.06 , thereby meeting the threshold suggested by Hu \& Bentler (1999). $(\chi 2=139.22 ; \mathrm{df}=71)$.

As in the original study, the convergent validity was assessed for the four constructs scales using three criteria suggested by Fornell and Larcker (1981): (1) all indicator factor loadings should be significant and exceed 0.7 , (2) construct reliabilities should exceed 0.80 , and (3) average variance extracted (AVE) by each construct should exceed the variance due to measurement error for that construct (AVE should exceed 0.50 ). The results indicate that construct reliability values ranged from 0.809 to 0.959 and AVE ranged from 0.585 to 0.855 , greater than variance due to measurement error. Therefore, all three conditions for convergent validity were met. The following table depicts the construct reliability values:

\begin{tabular}{|l|l|}
\hline \multicolumn{2}{|c|}{ Table 1. Construct Reliability } \\
\hline Construct & Reliability \\
\hline Perceived Usefulness & 0.929 \\
\hline Satisfaction & 0.959 \\
\hline Continuance Intention & 0.856 \\
\hline Confirmation & 0.809 \\
\hline
\end{tabular}

As for discriminant validity, Fornell \& Larcker (1981) recommend a test of discriminant validity, where the AVE for each construct should exceed the squared correlation between that construct and all others. The following table summarizes the scale properties and illustrates that all AVE values (bolded) exceed 0.5 and for each construct and the AVE exceeds the square correlation of all other constructs.

\begin{tabular}{|l|l|l|l|}
\hline \multicolumn{5}{|c|}{ Table 2. Construct Reliability } \\
\hline Perceived Usefulness & Satisfaction & Continuance Intention & Confirmation \\
\hline $\mathbf{0 . 7 6 7}$ & - & - & - \\
\hline 0.608 & $\mathbf{0 . 8 5 5}$ & - & - \\
\hline 0.748 & 0.727 & $\mathbf{0 . 6 6 7}$ & - \\
\hline 0.586 & 0.755 & 0.622 & $\mathbf{0 . 5 8 5}$ \\
\hline
\end{tabular}

\subsection{Hypothesis Testing}

We used AMOS version 23 with Maximum Likelihood technique to test the five hypotheses. The goodnessof-fit for the structural model shows adequate fit between the hypothesized model and the data $(\chi 2=139.72$; $\mathrm{df}=72, \mathrm{CMIN} / \mathrm{DF}=1.93, \mathrm{NFI}=0.957, \mathrm{CFI}=0.979, \mathrm{RMSEA}=0.06$ ). The following figure depicts the results of hypothesis testing. 


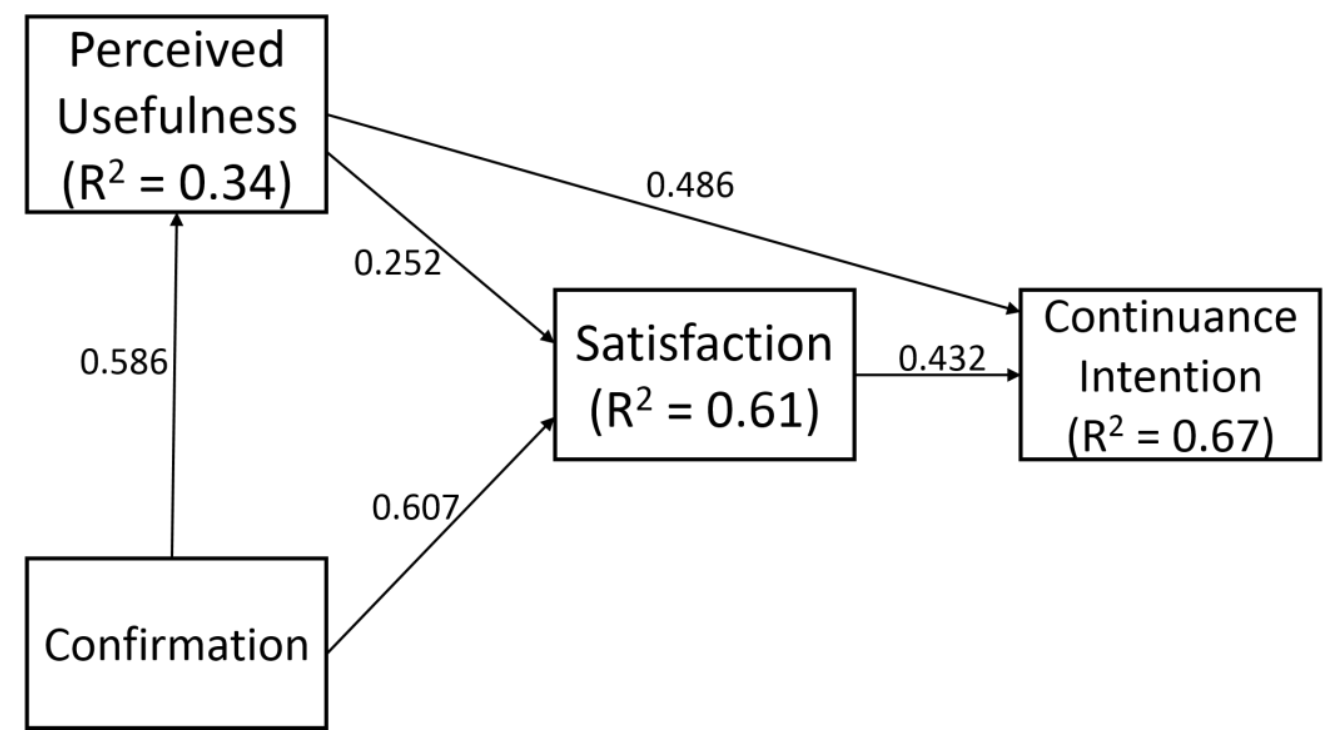

Figure 2. Analysis of Research Model

The analysis shows that all hypotheses are supported at $\mathrm{p}<0.01$ level. Continuance intention was predicted by satisfaction and perceived usefulness. Furthermore, perceived usefulness had a small indirect impact on the continuance intention through satisfaction construct. Satisfaction was also predicted by confirmation. Ultimately, confirmation predicted perceived usefulness.

Table 3 summarizes the comparison factors between the current and the original study:

\begin{tabular}{|c|c|c|}
\hline \multicolumn{3}{|c|}{ Table 3. Comparison Factors } \\
\hline Research Study Factor & The Original Study & The Replication Study \\
\hline Theoretical Foundations & Expectation-Confirmation Theory & same \\
\hline Experimental Design & Cross-sectional survey of users & same \\
\hline $\begin{array}{l}\text { Survey Environment and } \\
\text { Technology }\end{array}$ & $\begin{array}{l}\text { Late 1990s use of (web-based) online } \\
\text { banking }\end{array}$ & 2015 use of mobile banking apps \\
\hline Sampling Frame & $\begin{array}{l}1000 \text { random customers of one bank's } \\
\text { customers using online web-based } \\
\text { banking }\end{array}$ & $\begin{array}{l}529 \text { business students at a large } \\
\text { southeastern US university who are } \\
\text { customers of several different banks }\end{array}$ \\
\hline Response Rate & $12 \%(n=122)$ & $48 \%$ (usable $n=256$ ) \\
\hline Survey Platform & $\begin{array}{l}\text { Paper form } \\
\text { mailed with monthly statement }\end{array}$ & $\begin{array}{l}\text { Qualtrics - web-based online form } \\
\text { with URL found in survey invitation }\end{array}$ \\
\hline $\begin{array}{l}\text { Randomization of Survey Items (for } \\
\text { Common-Method Bias) }\end{array}$ & No & Yes \\
\hline Use of Attention Trap & No & Yes \\
\hline Analysis Tool & EQS & AMOS \\
\hline Hypotheses Supported & All five hypotheses supported. & All five hypotheses supported. \\
\hline $\begin{array}{l}\text { R-Squared for } \\
\text { The Dependent Variable }\end{array}$ & $41 \%$ & $67 \%$ \\
\hline
\end{tabular}

In the next section, we discuss the findings and make several suggestions for future research.

\section{Discussion and Conclusions}

The results of this conceptual replication indicate that IS Continuance Model, which was originally developed for online banking use, is also generalizable to mobile banking application use with high explanatory power, thus providing the theory contextualization called for by recent scholars. One of the interesting findings in this research concerns the path coefficient of the perceived usefulness to satisfaction association. In both the original model and in ours, this relationship has the lowest beta weight, compared to other relationships (0.227 in the original research and 0.252 in our research). In this regard, an updated version of IS 
Continuance Model (Bhattacherjee \& Lin, 2014), which integrates habitual behaviors into the original model, further emphasizes this point by excluding the "perceived usefulness" to "satisfaction" relationship. We argue that perceived usefulness is important for continuance use, but its effect is not dependent on satisfaction. Satisfaction captures past or realized user experience with the technology, whereas perceived usefulness represents expected benefits from future use (after the initial use). Hence, users can continue using the technology if they are satisfied with prior usage experience, or if they expect utility gains (perceived usefulness) from future usage, or both. Regarding the independent nature of these two effects, the strength of relationship between perceived usefulness and satisfaction is not strong. On the other hand, expectations of future benefits are usually influenced by prior experiences; this relationship is reflected in confirmationperceived usefulness association, which is a stronger relationship in both the original model and our paper (respectively, 0.525 and 0.607).

Another point of comparison is the sampling frame and response rate in the original paper and that of our replication research. The relatively low response rate in the original paper $(12 \%)$ might suggest the potential for non-response bias that could have negatively impacted the credibility and reliability of its findings. However, (1) the relatively higher response rate in this replication (48\%), (2) the larger sample (twice as many respondents), and (3) the broader technological platform (our respondents were customers of many banks, not a single bank) further support and validate the findings of the original study. The robustness of IS Continuance Model is also surfaced by its applicability in the modern context - mobile banking - which now dominates the interaction pattern of banking customers, especially younger ones. It should be noted that the original study and our replication focus on a voluntary and functional (not hedonistic) technology adoption and continuance that is generally not characterized by habitual behavior or addiction, so we cannot suggest our findings can be extended universally.

One of the limitations of this research, which is also attributable to the original study, is its cross-sectional data collection process. We note that beliefs, attitudes, and decisions are dynamic and as a result, crosssectional studies may not fully capture the complexity of post-adoption responses because of the longitudinal nature of the IT continuance phenomenon. Therefore, the results of such studies should be viewed as only preliminary evidence with respect to the varying criteria that predominate different phases of the technology post-adoption behaviors. Longitudinal studies which examine how each individual's beliefs and attitudes evolve temporally provide a more rigorous framework for understanding how the determinants of behavioral intention, attitude, and subjective norm change over time. Future research should focus on conducting longitudinal investigation and comparison of users' pre-adoption and post-adoption perceptions, which is vital to successful capturing of the complex and dynamic interrelationships between initial adoption and post-adoption decisions.

Overall, the findings of this study show that the IS Continuance Model, which was originally tested by surveying the users of web-based banking services of one bank, is valid in a modern context and is generalizable to mobile banking applications users. The results of our replication of this model - one of the most influential theories about IT use behavior - support and extend the earlier results, and provide a higher level of confidence for future studies that will apply this model as the theoretical lens for related phenomena. 


\section{References}

Andrich, D. (1978). A rating formulation for ordered response categories, Psychometrika 43(4), 561-573.

Bentler, P. M. (1989). EQS 6 structural equations program manual. Los Angeles: BMDP Statistic Software, 86-102.

Bhattacherjee, A. (2001). Understanding information systems continuance: an expectation-confirmation model. MIS Quarterly, 25(3), 351-370.

Bhattacherjee, A., \& Lin, C. P. (2014). A unified model of IT continuance: Three complementary perspectives and crossover effects. European Journal of Information Systems, 24(4), 364-373.

Cappelli, P., \& Sherer, P. D. (1991). The missing role of context in OB-the need for a meso-level approach. Research in Organizational Behavior, 13, 55-110.

De Guinea, A. O., \& Markus, M. L. (2009). Why break the habit of a lifetime? Rethinking the roles of intention, habit, and emotion in continuing information technology use. MIS Quarterly, 33(3), 433-444.

Dennis, A. R., \& Valacich, J. S. (2014). A replication manifesto. AIS Transactions on Replication Research, 1(1), 14.

Fornell, C., \& Larcker, D. F. (1981). Evaluating structural equation models with unobservable variables and measurement error. Journal of Marketing Research, 18(1), 39-50.

Hardesty, D.M, \& W.O. Bearden (2004). The use of expert judges in scale development: Implications for improving face validity of measures of unobservable constructs. Journal of Business Research, 57,98-107.

Hong, W., Chan, F. K., Thong, J. Y., Chasalow, L. C., \& Dhillon, G. (2013). A framework and guidelines for contextspecific theorizing in information systems research. Information Systems Research, 25(1), 111-136.

Hu, L. T., \& Bentler, P. M. (1999). Cutoff criteria for fit indexes in covariance structure analysis: Conventional criteria versus new alternatives. Structural Equation Modeling: A Multidisciplinary Journal, 6(1), 1-55.

Johns, G. (2006). The essential impact of context on organizational behavior. Academy of Management Review, 31(2), 386-408.

Joshi, A., \& Roh, H. (2009). The role of context in work team diversity research: A meta-analytic review. Academy of Management Journal, 52(3), 599-627.

Karahanna, E., Straub, D. W., \& Chervany, N. L. (1999). Information technology adoption across time: A crosssectional comparison of pre-adoption and post-adoption beliefs. MIS Quarterly, 23(2), 183-213.

Kerlinger, F. (1973). Foundations of behavioral research,. London: Holt Reinhart \& Winston.

Kim, S. S., \& Malhotra, N. K. (2005). A longitudinal model of continued IS use: An integrative view of four mechanisms underlying postadoption phenomena. Management Science, 51(5), 741-755.

McCune, B., \& Grace, J. B. (2002). Analysis of ecological communities, Gleneden Beach, OR: MjM software design, 233-256.

Olbrich, S., Frank, S., Gregor, S., Niederman, F., \& Rowe, F. (2016). On the merits and limits of replication and negation for IS research. Working Paper.

Oliver, R. L. (1980). A cognitive model of the antecedents and consequences of satisfaction decisions. Journal of Marketing Research, 17(4), 460-469.

Podsakoff, P. M., MacKenzie, S. B., Lee, J. Y., \& Podsakoff, N. P. (2003). Common method biases in behavioral research: a critical review of the literature and recommended remedies. Journal of Applied Psychology, 88(5), 879903.

Rennie, L. (1982). Research note: Detecting a response set to Likert-style attitude items with the rating model," Educational Research and Perspectives, 9(1), 114-118.

Salovaara, A., \& Merikivi, J. (2015). IS research progress would benefit from increased falsification of existing Theories. Paper presented at the European Conference on Information Systems, Munster, Germany.

Schmittlein, D. C., Cooper, L. G., \& Morrison, D. G. (1993). Truth in concentration in the land of (80/20) laws. Marketing Science, 12(2), 167-183. 
Seddon, P. B., \& Scheepers, R. (2012). Towards the improved treatment of generalization of knowledge claims in IS research: Drawing general conclusions from samples. European Journal of Information Systems, 21(1), 6-21.

Seddon, P. B., \& Scheepers, R. (2015). Generalization in IS research: A critique of the conflicting positions of Lee \& Baskerville and Tsang \& Williams. Journal of Information Technology, 30(1), 30-43.

Taylor, S., \& Todd, P. A. (1995a). Understanding information technology usage: A test of competing models. Information Systems Research, 6(2), 144-176.

Taylor, S., \& Todd, P. (1995b). Assessing IT usage: The role of prior experience. MIS Quarterly, 19(4), 561-570.

Whetten, D. A., Felin, T., \& King, B. G. (2009). The practice of theory borrowing in organizational studies: Current issues and future directions. Journal of Management, 35(3), 537-563. 


\section{Appendix A: Exploratory Factor Analysis}

Table A1: Rotated Component Matrix ${ }^{a}$

\begin{tabular}{|c|c|c|c|c|}
\hline & \multicolumn{4}{|c|}{ Component } \\
\hline & 1 & 2 & 3 & 4 \\
\hline $\mathrm{Cl} 1$ & .296 & .310 & .790 & .165 \\
\hline $\mathrm{Cl} 2$ & .198 & .240 & .740 & .256 \\
\hline $\mathrm{Cl} 3$ & .308 & .298 & .754 & .125 \\
\hline PU1 & .240 & .843 & .282 & .157 \\
\hline PU2 & .223 & .825 & .291 & .182 \\
\hline PU3 & .224 & .839 & .247 & .201 \\
\hline PU4 & .147 & .708 & .407 & .192 \\
\hline CNF1 & .266 & .128 & .093 & .847 \\
\hline CNF2 & .215 & .093 & .170 & .859 \\
\hline CNF3 & .289 & .395 & .307 & .546 \\
\hline S1 & .828 & .221 & .298 & .305 \\
\hline S2 & .804 & .257 & .311 & .328 \\
\hline S3 & .827 & .187 & .270 & .313 \\
\hline S4 & .789 & .223 & .269 & .308 \\
\hline
\end{tabular}

Extraction Method: Principal Component Analysis.

Rotation Method: Equamax with Kaiser Normalization.

$\mathrm{Cl}=$ Continuance Intention, $\mathrm{PU}=$ Perceived Usefulness,

$\mathrm{CNF}=$ Confirmation, $\mathrm{S}=$ Satisfaction. 


\section{Appendix B: Instrument - Survey Items}

Continuance intention: (7-point agree/disagree Likert scale)

- I I intend to continue using mobile banking applications rather than discontinue its use.

- My intentions are to continue using mobile banking applications than use any alternative means (traditional or web-based banking).

- If I could, I would like to discontinue my use of mobile banking applications (reverse coded).

Satisfaction: (7-point semantic differential scale)

How do you feel about your overall experience of mobile banking applications use?

- Very dissatisfied/Very satisfied

- Very displeased/Very pleased

- Very frustrated/Very contented

- Absolutely terrible/Absolutely delighted

Perceived Usefulness: (7-point agree/disagree Likert scale)

- Using mobile banking applications improves my performance in managing personal finances.

- Using mobile banking applications increases my productivity in managing personal finances.

- Using mobile banking applications enhances my effectiveness in managing personal finances.

- Overall, mobile banking applications is useful in managing personal finances.

Confirmation: (7-point agree/disagree Likert scale)

- My experience with using mobile banking applications was better than what I expected.

- The service level provided by mobile banking applications was better than what I expected.

- Overall, most of my expectations from using mobile banking applications were confirmed.

Demographic Questions

Age:

Experience with mobile banking (\# of years): 


\section{About the Authors}

Ali Vedadi is a doctoral candidate at Mississippi State University. His primary research focus is in IS postadoption behavior and behavioral cybersecurity issues. He has published in peer-reviewed scientific journals and conferences such as International Journal of Process Management and Benchmarking, Americas Conference on Information Systems, Big XII + MIS Conference, and International Conference on Innovation in Business, Economics, Marketing and E-Technology. He has also served as a reviewer for several journals and conferences.

Merrill Warkentin is Professor of MIS and the Drew Allen Endowed Fellow in the College of Business at Mississippi State University. His research, primarily on the impacts of organizational, contextual, and dispositional influences on individual behaviors in the context of information security and privacy, has appeared in MIS Quarterly, Decision Sciences, Journal of the AIS, European Journal of Information Systems, Information Systems Journal, Information \& Management, and others. He is the author or editor of seven books, and serves (or has served) as Associate Editor for MIS Quarterly, Information Systems Research, Decision Sciences, European Journal of Information Systems, Information \& Management, and other journals. He is Senior Editor of the AIS Transactions on Replication Research and an Eminent Area Editor for Decision Sciences. His work has been funded by NATO, NSF, NSA, DoD, Homeland Security, IBM, and others. He is the Program Co-Chair for the 2016 AIS Americas Conference on Information Systems (AMCIS).

Copyright ( 92016 by the Association for Information Systems. Permission to make digital or hard copies of all or part of this work for personal or classroom use is granted without fee provided that copies are not made or distributed for profit or commercial advantage and that copies bear this notice and full citation on the first page. Copyright for components of this work owned by others than the Association for Information Systems must be honored. Abstracting with credit is permitted. To copy otherwise, to republish, to post on servers, or to redistribute to lists requires prior specific permission and/or fee. Request permission to publish from: AIS Administrative Office, P.O. Box 2712 Atlanta, GA, 30301-2712 Attn: Reprints or via e-mail from ais@aisnet.org. 